\title{
Open-Label Study of Sleep Disturbances in Patients with Parkinson's Disease Treated with Rasagiline
}

\author{
Michel Panisset, Jean-Louis Stril, Manon Bélanger, Geneviève Lehoux, \\ Donna Coffin, Sylvain Chouinard, on behalf of The REST Study Group
}

\begin{abstract}
Background: The prevalence of sleep disturbances among patients with Parkinson's disease (PD) is estimated to occur in $37 \%$ to $98 \%$ of patients. Sleep disturbances have been associated with a reduced quality of life for patients with PD. The objective of this study was to assess the impact of rasagiline treatment on the severity of sleep disturbances among patients with idiopathic PD. Methods: In this open-label, multicentre study, 110 adult patients with idiopathic PD were treated with rasagiline either as monotherapy or as adjunct therapy. The primary endpoint was the change in severity of sleep disturbances, assessed with the PD Sleep Scale from baseline to month 2. Exploratory endpoints included change in daytime sleepiness, assessed with the Epworth Sleep Scale, treatment satisfaction measured with the Treatment Satisfaction Questionnaire for Medication, patient's overall improvement or deterioration over time measured with the Clinical Global Impression of Improvement, tolerability, and safety. Findings: Patients treated with rasagiline as mono- or adjunct therapy showed a statistically significant improvement in sleep quality after 2 months. There was no change in daytime sleepiness. Overall, patients were satisfied with rasagiline treatment with a mean Treatment Satisfaction Questionnaire for Medication [standard deviation] total score at month 2 of $68 \%$ [16.1]. At the end of study, 64 patients $(65.9 \%)$ were judged, by the investigator, as being at least minimally improved from baseline on the Clinical Global Impression of Improvement. Rasagiline was safe and well-tolerated. Interpretation: Rasagiline as mono- or adjunct-therapy may improve sleep experience in patients with PD in the short term.
\end{abstract}

RÉSUMÉ: Étude ouverte sur les troubles du sommeil chez les patients atteints de la maladie de Parkinson qui sont traités par la rasagiline. Contexte : La prévalence des troubles du sommeil chez les patients atteints de la maladie de Parkinson (MP) serait de 37\% à 98\%. Les troubles du sommeil ont été associés à une qualité de vie diminuée chez ces patients. L'objectif de cette étude était d'évaluer l'impact du traitement par la rasagiline sur la sévérité des troubles du sommeil chez les patients atteints d'une MP idiopathique. Méthodologie : Dans cette étude multicentrique ouverte, 110 patients adultes atteints de MP idiopathique ont été traités par la rasagiline, soit en monothérapie ou comme traitement d'appoint. Le critère d'évaluation principal était le changement dans la sévérité des troubles du sommeil évalué au moyen de l'échelle du sommeil pour la MP au début de l'étude et après 2 mois de traitement. Les critères d'évaluation exploratoires incluaient le changement dans la somnolence diurne évalué au moyen de l'échelle de somnolence d'Epworth, la satisfaction par rapport au traitement mesurée au moyen du Treatment Satisfaction Questionnaire for Medication, l'amélioration ou la détérioration globale du patient dans le temps mesurée au moyen du questionnaire sur l'impression clinique globale d'amélioration, de tolérabilité et de sécurité. Résultats : Les patients traités par la rasagiline en monothérapie ou comme traitement d'appoint éprouvaient une amélioration significative au point de vue statistique de la qualité du sommeil après 2 mois de traitement. La somnolence diurne demeurait inchangée. Globalement, les patients étaient satisfaits du traitement par la rasagiline et le score total moyen au Treatment Satisfaction Questionnaire for Medication était de 68\% (écart type 16,1) après 2 mois. Le chercheur considérait que 64 patients (65,9\%) présentaient une amélioration au moins minimale par rapport à l'évaluation initiale à l'échelle d'impression clinique globale d'amélioration. La rasagiline était sûre et bien tolérée. Conclusion : La rasagiline en monothérapie ou comme traitement d'appoint peut améliorer le sommeil à court terme chez les patients atteints de la MP.

Keywords: Parkinson disease, Sleep, Rasagiline

doi:10.1017/cjn.2016.289

Can J Neurol Sci. 2016; 43: 809-814

Amongst the nonmotor symptoms (NMS) of Parkinson's disease (PD), sleep disturbances is the most frequent and occurs in $37 \%$ to $98 \%$ of patients. ${ }^{1-5}$ Sleep disturbances in
PD may be linked to resurgence of PD symptoms, anxiety, nocturia, PD medications, or an actual sleep disorder. ${ }^{6}$ Insomnia is the most common sleep problem in PD. Sleep disturbances

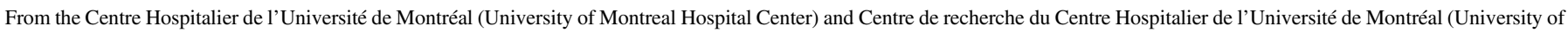

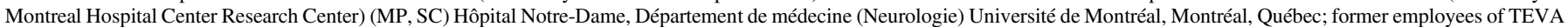
Canada Innovation (J-LS, MB, GL), Montréal, Québec; Boolean Research Consulting Services (DC), Montreal, Québec.

Received May 19, 2015. Final Revisions Submitted December 27, 2015. Date of Acceptance February 15, 2016.

Correspondence to: Michel Panisset, CHUM - Hôpital Notre-Dame, Montreal, Québec, 1560, rue Sherbrooke Est, Montréal, Québec, H2L 4M1 Canada. Email: michel.panisset@ umontreal.ca. 
in patients with PD has been associated with reduced quality of life. ${ }^{2,7,8}$

The treatment of sleep disturbances in PD is largely unstudied. Doxepin was recently shown to improve insomnia. ${ }^{9}$ The effects of levodopa on sleep are conflicting, with studies demonstrating a frequent disruption in sleep, ${ }^{10,11}$ and another showing an improvement in sleep. ${ }^{12}$ Dopaminergic agonists, anticholinergics, selegiline, and amantadine are also known to affect night-time sleep. ${ }^{13,14}$ Recent reports have shown that anti-Parkinson therapies can help nocturnal sleep disturbances in PD. ${ }^{15-23}$

Rasagiline, a selective irreversible inhibitor of the MAO-B enzyme, is a well-established treatment for PD, either as a monotherapy or adjunct therapy. ${ }^{24-27}$ The effect of rasagiline on sleep was assessed in an observational 8-week study $(n=26)^{28}$ and showed not statistically significant improvement in PD Sleep Scale (PDSS) total score. Switching patients from selegiline to rasagiline significantly improved sleep in PD patients. ${ }^{29}$

This study aimed to further evaluate the effects of rasagiline on the quality of sleep using the validated PDSS as the primary outcome measure.

\section{Methods}

\section{Patients}

Sixteen centres in Canada participated between December 2009 and March 2011. Eligible candidates were patients with a diagnosis of idiopathic PD who had not used selegiline or rasagiline within 60 days before study entry. Rasagiline was prescribed to all patients, either as monotherapy or adjunct therapy. The study was approved by ethics committees, and all patients provided written informed consent before enrolment. This study has been registered on clinicaltrials.org under the number NCT01032486.

\section{Design}

This was a single arm, open-label, multicentre study. Patients were followed prospectively during the 2-month study period while treated with a daily dose of rasagiline $(0.5 \mathrm{mg}$ or $1.0 \mathrm{mg})$. Rasagiline could be up-titrated $(0.5 \mathrm{mg}$ to $1.0 \mathrm{mg})$ or downtitrated ( $1.0 \mathrm{mg}$ to $0.5 \mathrm{mg}$ ), as per physician discretion during the 60 -day period of the study. This study was not intended to examine a dose-response relationship.

\section{Timeline and Clinical Assessments}

Demographic and clinical characteristics of the patients were recorded at study entry. Baseline assessments included the PDSS, the Epworth Sleepiness Scale (ESS), and the Hoehn and Yahr staging scale (H\&Y). The end of study visit, at month 2, included administration of the PDSS, ESS, and Clinical Global Impression of Improvement (CGI-I), Treatment Satisfaction Questionnaire for Medication (TSQM), assessment of treatment compliance by patient report, and safety and tolerability.

\section{Assessment of Nocturnal Symptoms}

The PDSS is a self-administered questionnaire designed to evaluate the frequency and specific nature of sleep disturbances experienced during the week preceding administration. ${ }^{30}$ The scale consists in eight subscales: overall quality of sleep (Q1); sleep onset and maintenance insomnia (Q2, Q3); nocturnal restlessness (Q4, Q5); nocturnal psychosis (Q6, Q7); nocturia (Q8, Q9); nocturnal motor symptoms (Q10-Q13); sleep refreshment (Q14); and daytime dozing (Q15). The severity of each symptom is measured on a visual analog scale, ranging from 0 to 100 , with higher scores indicating a better quality of sleep.

The ESS is a self-administered, eight-item questionnaire designed to measure a patients' general level of daytime sleepiness. ${ }^{31,32}$ Higher éESS scores indicate a higher level of daytime sleepiness.

The CGI-I is a brief clinician-rated instrument, which provides an estimate of the patient's overall improvement or deterioration over time. ${ }^{33}$

The TSQM (version 1.4) is a self-administered, 14-item general measure of patients' satisfaction with medication. ${ }^{34}$

The H\&Y allows a staging of parkinsonism that is in keeping with the natural evolution of the disease and is independent of response to therapy (fluctuations).

\section{Statistical Analysis}

The primary endpoint was the change from baseline to month 2 in total PDSS score. The secondary endpoint was the change from baseline to month 2 in the ESS score. Exploratory endpoints included change from baseline to month 2 in the subscales of the PDSS and in the other scales. Safety and tolerability were measured by incidence of adverse events (AEs), serious AEs, premature discontinuation of rasagiline overall, and discontinuation because of AEs.

A sample size of 119 patients was determined to detect a $10 \%$ difference between baseline and end of study in total PDSS, with a power of $80 \%$ and a $5 \%$ two-sided significance threshold. A difference of $10 \%$ between baseline and month 2 was considered to be clinically significant based on previous studies. ${ }^{7,28}$ This estimation assumes a baseline PDSS score of 100, standard deviation (SD) of 34 , and a $10 \%$ drop out rate. ${ }^{7,30,35}$ A correction by a factor of 1.157 was introduced into the estimate to account for the possibility of a non-normal distribution, requiring use of a Wilcoxon signed-rank test. All results were analyzed in the modified intention-to-treat (mITT) population, defined as all patients who enrolled in the study and had both a baseline and month 2 (end of study) visits.

Demographic and baseline characteristics of the ITT population were presented descriptively. Change in PDSS total and subscale scores at month 2 was assessed using a Wilcoxon signedrank test to test the hypothesis of no difference in median PDSS scores from baseline to end of study. Shapiro-Wilk tests were conducted to verify the normality of the distribution and a paired t-test was conducted under conditions of a normal distribution, as supportive analysis. The ESS total and the ESS subscales were tested in a similar manner.

The CGI-I and TSQM assessment scales were reported with descriptive statistics on their total scores.

A post hoc analysis was conducted in which patients were classified as having mild or troublesome sleep disturbances using the median PDSS score at baseline as the cutoff value. This subgroup analysis was conducted for the total PDSS score as well as for each of the subscales. Subscales scores were differentiated by $<5$ and $\geq 5$, indicating troublesome and mild sleep problems, respectively. Post hoc analysis of change in total ESS score 
Table 1: Demographic and clinical characteristics of patients

\begin{tabular}{|c|c|c|}
\hline & $\begin{array}{c}\text { ITT } \\
\mathbf{N}=110\end{array}$ & $\begin{array}{c}\text { mITT } \\
\mathbf{N}=97\end{array}$ \\
\hline Age, years, mean (SD) & $66.9(9.4)$ & $66.1(9.1)$ \\
\hline Male, n (\%) & $83(75.5)$ & $75(77.3)$ \\
\hline Caucasian, n (\%) & $97(88.2)$ & $84(86.6)$ \\
\hline Disease duration, years, median (range) & $3(0-28)$ & $3(0-28)$ \\
\hline \multicolumn{3}{|l|}{ H\&Y stage, $\mathrm{n}(\%)$} \\
\hline 1.0 & $20(18.2)$ & $18(18.6)$ \\
\hline 1.5 & $14(12.7)$ & $13(13.4)$ \\
\hline 2.0 & $49(44.5)$ & $47(48.5)$ \\
\hline 2.5 & 15 (13.6) & $12(12.4)$ \\
\hline 3.0 & $9(8.2)$ & $5(5.2)$ \\
\hline 4.0 & $3(2.7)$ & $2(2.1)$ \\
\hline 5.0 & 0 & 0 \\
\hline \multicolumn{3}{|l|}{ Rasagiline treatment, $\mathrm{n}(\%) *$} \\
\hline Monotherapy & $14(12.7)$ & $14(14.4)$ \\
\hline Adjunct therapy & $96(87.3)$ & $83(85.6)$ \\
\hline $0.5 \mathrm{mg}$ dose & $60(54.5)$ & $53(54.6)$ \\
\hline Dose up-titrated to $1.0 \mathrm{mg}, \mathrm{n}(\%)$ & $27(24.5)$ & $27(27.8)$ \\
\hline $1.0 \mathrm{mg}$ dose & $50(45.5)$ & $44(45.6)$ \\
\hline Dose down-titrated to $0.5 \mathrm{mg}, \mathrm{n}(\%)$ & $2(1.8)$ & $1(<1)$ \\
\hline Treatment duration, days, mean (SD) & $61(17.1)$ & $66(9.5)$ \\
\hline \multicolumn{3}{|l|}{ Number of missed doses, $\mathrm{n}(\%)$} \\
\hline None & $71(66.4)$ & $68(70.1)$ \\
\hline$<5$ & $26(24.3)$ & $26(26.8)$ \\
\hline $5-15$ & $1(1)$ & $1(1)$ \\
\hline$>15$ & $9(8.4)$ & $2(2.1)$ \\
\hline
\end{tabular}

*Rasagiline dose prescribed at baseline.

stratified by mean baseline ESS score $(<4.6=$ mild daytime sleepiness vs $\geq 4.6=$ troublesome daytime sleepiness) was also conducted and reported descriptively.
The statistical design and analysis was performed using SAS, version 9.2 .

\section{RESULTS \\ Patient Disposition}

A total of 120 patients were enrolled in the study; 110 received rasagiline. Reasons for nontreatment were withdrawal of consent $(n=5)$, physician decision $(n=1)$, noncompliance of study requirement $(n=1)$, and other $(n=3)$. Overall, $97(88 \%)$ of the treated patients completed the study. The most common reason for premature discontinuation in 13 patients $(11.8 \%)$ was due to AEs $(\mathrm{n}=11,10 \%)$. One $(<1 \%)$ patient discontinued by stopping medication permanently on day 2 of the study and another withdrew consent $(n=1,<1 \%)$. One patient was excluded from the primary analysis of PDSS and four patients were excluded from the ESS analysis because missing data.

\section{Baseline Characteristics}

The mean [SD] age of the 110 patients was 67 [9.4] years and $75 \%$ were male. Participants were diagnosed with PD a median (range) of $3(0-28)$ years before enrolment and the majority of patients were in $\mathrm{H} \& \mathrm{Y} 1$ to 1.5 or 2 to 2.5 (i.e. bilateral symptoms with or without postural instability). The majority of patients were on adjunct therapy. The ITT and mITT groups were similar with the exception that nine patients in the ITT population and two from the mITT population missed $>15$ doses (Table 1 ).

\section{Sleep Disturbances PDSS}

Sleep disturbances improved significantly after 2 months of treatment as assessed by the PDSS (Table 2). At baseline, total mean [SD] PDSS score was 96.2 [21.6], which improved to 105.5 (21.9) at month 2, (mean [SD] improvement of 9.11 [18.69] points, $\mathrm{p}=0.003$ ). The primary endpoint of this study was met and was confirmed by a paired t-test analysis.

Results with the subscales of the PDSS are shown in Table 2.

Table 2: PDSS total and subscale scores

\begin{tabular}{|c|c|c|c|c|c|}
\hline \multirow[b]{2}{*}{ Scales and subscales } & \multicolumn{2}{|c|}{ PDSS scores } & \multirow[b]{2}{*}{$\begin{array}{l}\text { Change from baseline to month } 2 \\
\text { Mean (SD) }\end{array}$} & \multirow[b]{2}{*}{$\begin{array}{c}\text { Percent change over baseline }(\%, \mathrm{CI}) \\
\text { Mean (SD) }\end{array}$} & \multirow[b]{2}{*}{ p value* } \\
\hline & $\begin{array}{c}\text { Baseline } \\
\text { Mean (SD) N }=96\end{array}$ & $\begin{array}{c}\text { Month } 2 \\
\text { Mean (SD) N }=96\end{array}$ & & & \\
\hline Total & $96.2(21.6)$ & $105.5(21.9)$ & $9.11(18.69)$ & $7(-33.9,276.6)$ & 0.003 \\
\hline Overall quality of sleep & $5.5(2.3)$ & $6.3(2.2)$ & $0.76(2.22)$ & 41.5 (144.6) & 0.01 \\
\hline Sleep onset/maintenance insomnia $\dagger$ & $6.0(2.3)$ & $6.5(2.1)$ & $0.45(2.29)$ & $40.6(206.5)$ & 0.1 \\
\hline Nocturnal restlessness & $6.6(2.3)$ & $7.4(2.2)$ & $0.70(2.10)$ & $35.9(177.7)$ & 0.01 \\
\hline Nocturnal psychosis $\ddagger$ & $7.4(2.1)$ & $8.0(1.7)$ & $0.52(1.72)$ & $17(61.9)$ & 0.06 \\
\hline Nocturia: & $5.6(2.0)$ & $6.1(2.0)$ & $0.48(1.79)$ & $123.9(1031.7)$ & 0.2 \\
\hline Nocturnal motor symptoms & $7.0(1.9)$ & $7.7(1.8)$ & $0.58(1.49)$ & $13.2(41.6)$ & 0.01 \\
\hline Sleep refreshment: & $5.4(2.8)$ & $6.3(3.0)$ & $0.91(3.13)$ & $77.3(257.3)$ & 0.02 \\
\hline Daytime dozing & $5.9(3.1)$ & $6.7(2.9)$ & $0.72(2.74)$ & $116.0(538.3)$ & 0.1 \\
\hline
\end{tabular}

*Wilcoxon signed-rank test for median change from baseline to month 2, mITT population.

$\dagger \mathrm{n}=94,2$ patients had missing data to $\geq 1$ question.

$\ddagger \mathrm{n}=95,1$ patient had missing data to $\geq 1$ question. 
The subscales that were the most troublesome for patients at baseline were sleep refreshment, overall quality of sleep, nocturia, and daytime dozing (visual analog scale scores $<6$ ). Nocturnal psychosis and nocturnal motor symptoms were the least troubling at baseline (visual analog scale scores $>7$ ).

The mean [SD] ESS score improved slightly over the study, from 10 [5.2] at baseline to 9.4 [5.0] at month $2(p=0.4407)$.

Overall, patients were satisfied with rasagiline treatment with a mean [SD] TSQM total score at month 2 of $68 \%$ [16.1]. Patients were more satisfied with rasagiline in terms of convenience $(82.3 \%$ [16.3]) and side effects $(85.4 \%$ [23.8]) than effectiveness (53.9\% [20.1]) or global satisfaction (51\% [24.6]).

On the CGI-I at month 2, $64(65.9 \%)$ patients were judged by the investigator as being at least minimally improved from baseline and 27 [27.8\%] were reported to have had no change. Only six patients $(6.2 \%)$ worsened.

A post-hoc analysis of change in PDSS total score, stratified by median baseline PDSS score (96.9 points), was conducted. Both groups of patients, those with troublesome (PDSS <96.9) and mild (PDSS $\geq 96.9$ ) sleep disturbances had statistically significant improvements at month 2 . The treatment effect at month 2 for the PDSS total score was larger for patients with troublesome sleep disturbances (12 points, median $\%$ change $15.6, p=0.0013)$ than for patients with mild sleep disturbances (5.9 points, median percent change $5.2, \mathrm{p}=0.0099)$ at baseline.

The change in each of the PDSS subscales, stratified by baseline score $(<5, \geq 5)$, was significant $(\mathrm{p}<0.05)$ at month 2 for patients with troublesome sleep disturbances $(<5)$. Patients with mild sleep disturbances $(\geq 5)$ did not experience the same statistical improvement in any of the subscales, with the exception of nocturnal motor symptoms, which was significantly improved $(\mathrm{p}<0.05)$.

\section{Safety}

Forty-two (38.2\%) patients reported at least one treatment emergent AE during the study. The most common AEs reported were nausea $(n=6,5.5 \%)$, dizziness $(n=4,3.6 \%)$, constipation $(\mathrm{n}=3,2.7 \%)$, diarrhea $(\mathrm{n}=3,2.7 \%)$, visual hallucination $(\mathrm{n}=3,2.7 \%)$, and somnolence $(\mathrm{n}=3,2.7 \%)$. Most events were mild or moderate in nature and all, with the exception of dizziness and diarrhea, were considered to be possibly related to rasagiline. Serious AEs occurred in three $(2.7 \%)$ patients and were contributory to the discontinuation of rasagiline treatment: one patient died of a heart condition of unknown etiology on day 31 of the study and was deemed not related to rasagiline; another patient experienced a severe fall on day 9 of the study, for which she was hospitalized and which was assessed as being possibly related to rasagiline; and the third patient was diagnosed with prostate cancer on day 25 , not related to study drug. A total of $13(12 \%)$ patients discontinued rasagiline because of an AE (including the three serious AEs). The only AE leading to drug discontinuation occurring in $>1$ patient was dizziness, which occurred in 2 patients. Eleven (10\%) of the AEs leading to drug discontinuation were considered possibly related to rasagiline.

\section{DISCUSSION}

We found that rasagiline is effective at improving the quality of sleep in patients with idiopathic PD. Over 2 months, patients taking rasagiline, as monotherapy or adjunct therapy, experienced significant decreases in overall sleep disturbances and improvements in quality of sleep, nocturnal restlessness, nocturnal motor symptoms, and sleep refreshment. In addition, the majority of patients were satisfied with the medication, in particular for its manageable side effect profile and convenience. Sixty-six percent of patients showed improvement over the 2-month treatment period as per physician rating on the CGI.

No new safety issues emerged from this study and AEs were typically mild or moderate in nature.

Although there were no specific measures to assess the mechanism by which rasagiline improves sleep quality, it is likely that its irreversible MAO-B inhibition extends its benefits overnight. ${ }^{36,37}$ The majority of sleep disturbances associated with PD are due to reemergence of parkinsonian symptoms during the night. Rasagiline was shown to improve motor scores during the "practically defined OFF state" indicating that once-daily treatment with rasagiline exerts a continuous clinical effect of $\geq 24$ hours. ${ }^{38}$ Other long-acting dopaminergic drugs, levodopa/carbidopa infusion technique, and deep brain surgery have shown similar effects in populations affected with similar sleep scores. ${ }^{15-23}$

We also found that patients' sleep symptoms respond differentially to rasagiline, based on their severity. Troublesome sleep problems, defined by the median PDSS total score $(\leq 96)$, conferred large improvements, whereas milder sleep problems (PDSS > 96) showed smaller, although still statistically significant, improvements. Although four of the subscales of the PDSS were significantly improved at month 2 for the total study population, all eight subscales were improved for patients with troublesome sleep disturbances. Only one subscale, nocturnal motor symptoms, was significantly improved for patients with mild or no sleep disturbances at baseline. This may be due to a ceiling effect, in that patients with mild symptoms have little room for improvement, whereas those with troublesome symptoms and a lower baseline PDSS score have room to improve. Patients with mild sleep disturbance at baseline had a median (range) of 110.8 (96.9-144.5) points on total PDSS, which improved to 119.9 (80.2-149.0) at month 2, which approximates the mean of 120 on total PDSS seen in healthy populations. ${ }^{30,35}$ Patients with troublesome nocturnal symptoms at baseline had a median total PDSS score of 84.3 (27.8-96.8), which improved to 94.7 (36.5-126.2) at month 2.

Assessing treatment effects by severity of sleep disturbances at baseline was also studied by Chaudhuri. ${ }^{7}$ Similarly, they found patients with troublesome nocturnal symptoms responded more favourably to ropinirole versus placebo, whereas patients with mild-no nocturnal symptoms showed no treatment effect.

\section{Limitations}

This study used an uncontrolled open-label design, thus it is not possible to conclude that the patients would not have experienced an improved quality of sleep in the absence of rasagiline. Also, with this type of protocol design, it is impossible to quantify the placebo effect. However, given the progressive nature of PD symptoms, it is unlikely that patients would experience an improvement of this magnitude spontaneously. More than $85 \%$ of patients were on adjunct therapy. This may affect the generalizability of the study results to patients on monotherapy, however, no difference in PDSS total score was found when stratified by rasagiline monotherapy versus adjunct therapy.

In summary, this open-label study demonstrates that rasagiline improves sleep experience in patients with idiopathic PD in the 
short term. These encouraging results might stimulate future research with a double-blind, randomized study design.

\section{ACKNOWLEDGEMENTS AND FUNDING}

The authors thank Marie-Claude Guertin and Mariève Cossette of the Montreal Heart Institute Coordinating Center for statistical analysis. The authors also thank Lyne Jean for administrative and secretarial support.

This study was funded by TEVA Canada Innovation.

\section{Disclosures}

MP has received honoraria from TEVA, Novartis, Allergan, and Merz. J-LS and MB were employees of TEVA Canada Innovation and received an annual salary; they held stock options from TEVA Canada Innovation. J-LS is an employee of Novartis Pharma Canada and receives a salary. GL was an employee of TEVA Canada Innovation during the time this study was conducted. DC has received financial compensation for the drafting of the manuscript. SC has been a consultant for and has received honoraria from TEVA, Novartis, Allergan, Merz, and Abbott.

\section{Author Contributions}

MP, J-LS, MB, and GL contributed to the design and conceptualization of the study, and interpretation of data; Donna Coffin, MSc: wrote first draft of manuscript and interpretation of data; and SC contributed to the design and conceptualization of the study, and interpretation of data.

\section{REFERENCES}

1. Chaudhuri KR, Odin P. The challenge of non-motor symptoms in Parkinson's disease. Prog Brain Res. 2010;184:325-41.

2. Barone P, Antonini A, Colosimo C, et al. The PRIAMO study: a multicenter assessment of nonmotor symptoms and their impact on quality of life in Parkinson's disease. Mov Disord. 2009;24:1641-9.

3. Kumar S, Bhatia M, Behari M. Sleep disorders in Parkinson's disease. Mov Disord. 2002;17:775-81.

4. Lees AJ, Blackburn N, Campbell VL. The nighttime problems of Parkinson's disease. Clin Neuropharmaco. 1988;11:512-9.

5. Tandberg E, Larsen JP, Karlsen K. A community-based study of sleep disorders in patients with Parkinson's disease. Mov Disord. 1998; 13:895-9.

6. Verbaan D, van Rooden S, Visser M, Marinus J, van Hilten JJ. Nighttime sleep problems and daytime sleepiness in Parkinson's disease. Mov Disord. 2008;23:35-41.

7. Chaudhuri R, Martinez-Martin P, Rofle KA, et al. Improvements in nocturnal symptoms with ropinirole prolonged release in patients with advanced Parkinson's disease. Eur J Neurol. 2011;19: 105-13.

8. Gallagher DA, Lees AJ, Schrag A. What are the most important nonmotor symptoms in patients with Parkinson's disease and are we missing them? Mov Disord. 2010;25:2493-500.

9. Rios Romenets S, Creti L, Fichten C, et al. doxepin and cognitive behavioral therapy for insomnia in patients with Parkinson's disease - a randomized study. Parkinsonism Relat Disord. 2013;19:670-5

10. Nausieda PA, Weiner WJ, Kaplan LR, Weber S, Klawans HL. Sleep disruption in the course of chronic levodopa therapy: an early feature of the levodopa psychosis. Clin Neuropharmacol. 1982;5:183-94.

11. Antczak JM, Rakowicz MJ, Banach M, et al. Negative influence of L-dopa on subjectively assessed sleep but not on nocturnal polysomnographiy in Parkinson's disease. Pharmacol Rep. 2013; 65:614-23.

12. Askenasy JJ, Yahr MD. Reversal of sleep disturbance in Parkinson's disease by antiparkinsonian therapy: a preliminary study. Neurology. 1985;35:527-32.

13. Adler CH, Thorpy MJ. Sleep issues in Parkinson's disease. Neurology. 2005;64(12 Suppl 3):S12-20.

14. Chahine LM, Daley J, Horn S, et al. Association between dopaminergic medications and nocturnal sleep in early stage Parkinson's disease. Parkinsonism Relat Disord. 2013;19:859-63.

15. Trenkwalder C, Kies B, Rudzinska M, et al. Recover Study Group. Rotigotine effects on early morning motor function and sleep in Parkinson's disease: a double-blind, randomized, placebocontrolled study (RECOVER). Mov Disord. 2011;26:90-9.

16. Canesi M, Mariani CB, Isaias IU, Pezzoli G. Night-time use of rotigotine in advanced Parkinson's disease. Funct Neurol. 2010; 25:201-4.

17. Giladi N, Fichtner A, Poewe W, Boroojerdi B. Rotigotine transdermal system for control of early morning motor impairment and sleep disturbances in patients with Parkinson's disease. J Neural Transm. 2010;117:1395-9.

18. Chaudhuri KR, Martinez-Martin P, Antonini A, et al. Rotigotine and specific non-motor symptoms of Parkinson's disease: a post hoc analysis of RECOVER. Parkinsonism Relat Disord. 2013; 19:660-5.

19. Chaudhuri RK, Martinez-Martin P, Rolfe KA, et al. Improvements in nocturnal symptoms with ropinirole prolonged release in patients with advanced Parkinson's disease. Eur J Neurol. 2012;19:105-13.

20. Romigi A SP, Marciani MG, Izzi F, et al. Effect of cabergoline added to levodopa treatment on sleep-wake cycle in idiopathic Parkinson's disease: an open label 24-hour polysomnographic study. J Neural Transm. 2006;113:1909-13.

21. Reichmann H, Cooper J, Rolfe K, Martinez-Martin P. Sleep duration and "on" time during different periods of the day and night in patients with advanced Parkinson's disease receiving adjunctive ropinirole prolonged release. Parkinsons Dis. 2011;2011:1-8.

22. Zibetti M, Rizzone ZM, Angrisano MA, et al. Sleep improvement with levodopa/carbidopa intestinal gel infusion in Parkinson Disease. Acta Neurol Scand. 2013;127:e28-32.

23. Amara AW, Standaert DG, Guthrie S, et al. Unilateral subthalamic nucleus deep brain stimulation improves sleep quality in Parkinson's disease. Parkinsonism Relat Disord. 2012;18:63-8.

24. Parkinson Study Group. A controlled trial of rasagiline in early Parkinson disease: the TEMPO Study. Arch Neurol. 2002;59:1937-43.

25. Parkinson Study Group. A randomized placebo-controlled trial of rasagiline in levodopa-treated patients with Parkinson disease and motor fluctuations: the PRESTO study. Arch Neurol. 2005; 62:241-8.

26. Rascol O, Brooks DJ, Melamed E, et al. Rasagiline as an adjunct to levodopa in patients with Parkinson's disease and motor fluctuations (LARGO, Lasting effect in Adjunct therapy with Rasagiline Given Once daily, study): a randomised, double-blind, parallel-group trial. Lancet. 2005;365:947-54.

27. Olanow CW, Hauser RA, Jankovic J, et al. A randomized, double-blind, placebo-controlled, delayed start study to assess rasagiline as a disease modifying therapy in Parkinson's disease (the ADAGIO study): rationale, design, and baseline characteristics. Mov Disord. 2008;23:2194-201.

28. Müller T, Klasser M, Rieke J, Ries S, Schwartz G, Ehret R, and the Rasagiline Sleep Disturbances Study Group. Effect of rasagiline on sleep disturbances and fatigue in patients with Parkinson's disease: a pilot study. Poster session presented at: 6th International Congress on Mental Dysfunctions \& Other Non-Motor Features in Parkinson's Disease; October 16-19, 2008; Dresden, Germany.

29. Müller T, Hoffmann JA, Dimpfel W, Oehlwein C. Improvements in sleep and mood after switch of Parkinson's disease patients (PD) from selegiline to rasagiline. Eur J Neurol. 2011;18:244.

30. Chaudhuri KR, Pal S, DiMarco A, et al. The Parkinson's disease sleep scale: a new instrument for assessing sleep and nocturnal disability in Parkinson's disease. J Neurol Neurosurg Psychiatry. 2002;73:629-35. 
31. Johns MW. A new method for measuring daytime sleepiness: the Epworth sleepiness scale. Sleep. 1991;14:540-5.

32. Johns MW. Reliability and factor analysis of the Epworth Sleepiness Scale. Sleep. 1992;15:376-81.

33. Forkmann T, Scherer A, Boecker M, Pawelzik M, Jostes R, Gauggel $\mathrm{S}$. The Clinical Global Impression Scale and the influence of patient or staff perspective on outcome. BMC Psychiatry. 2011;11:83.

34. Atkinson MJ, Sinha A, Hass SL, et al. Validation of a general measure of treatment satisfaction, the Treatment Satisfaction Questionnaire for Medication (TSQM), using a national panel study of chronic disease. Health Qual Life Outcomes. 2004;2:12.

35. Abe K, Hikita T, Sakoda S. Sleep disturbances in Japanese patients with Parkinson's disease-comparing with patients in the UK. J Neurol Sci. 2005;234:73-8.

36. Chen JJ, Swope DM. Clinical pharmacology of rasagiline: a novel, second-generation propargylamine for the treatment of Parkinson disease. J Clin Pharmacol. 2005;45:878-94.

37. Thebault JJ, Guillaume M. Phase I clinical trials of TVP-1012 (rasagiline mesylate), a selective inhibitor of monoamine oxidase B, for treatment of Parkinson's disease. Move Disord. 1997; 12(Suppl 1):106.

38. Stocchi F, Rabey JM. Effect of rasagiline as adjunct therapy to levodopa on severity of OFF in Parkinson's disease. Eur J Neurol. 2011;18:1373-8.

\section{APPENDIX 1 \\ Co-Investigators:}

Richard Leckey, MD (Parkland Medical Clinic, Halifax, NS); André F. Gagnon, MD (Polyclinique de Trois-Rivières, TroisRivières, QC); Stéphanie Jacques, MD (Cabinet médical spécialisé États d'Esprit, Rouyn-Noranda, QC); Xuan Khoa Phan, MD (Centre médical Pierre-Boucher, Longueuil, QC); Robert Filiatrault, MD (Clinique Neuro Rive-Sud, Greenfield Park, QC); Hyman Rabinovitch, MD (Nepean Medical Centre, Ottawa, ON); François Jacques, MD (Clinique Neuro-Outaouais, Gatineau, QC); Sherali Esmail, MD (North York, ON); Dwight Stewart, MD (Kitchener, ON); Mélanie Langlois, MD (Hôpital de l'enfantJésus, Québec, QC); Roberto Giaccone, MD (Ottawa, ON); Louise Roux, MD (Clinique Médicale D’Amos, Amos, QC), Paul A. Hwang, MD (Toronto, ON); Michel Beaudry, MD (Clinique de Neurologie, Chicoutimi, QC); Léo Berger, MD (Clinique Neuro Rive-Sud, Greenfield Park, QC); Emmanuelle Pourcher, MD (Clinique Sainte-Anne "Mémoire et Mouvement," Ste Foy, QC). 